\title{
Effect of annealing temperature on crystalline formation and electrochemical behavior of $\varepsilon-\mathrm{MnO}_{2}$ nanoparticle
}

\author{
P. Muhammed Shafi and A. Chandra. Bose* \\ Nanomaterials Laboratory, Department of Physics \\ National Institute of Technology, Tiruchirappalli- 620015 \\ *Email: acbose@nitt.edu
}

In recent years, the large scale energy production and developments in renewable energy sources require highly efficient energy storage systems. The physical and chemical charge storage techniques along with high power and energy density brought electrochemical supercapacitors (ECs) as a versatile power source. Since the last couple of decades, supercapacitors with various metal oxides as electrode materials got a great interest among researchers. Here, we demonstrate manganese oxide $\left(\mathrm{MnO}_{2}\right)$ nanomaterials as supercapacitor electrodes (Figure 1).

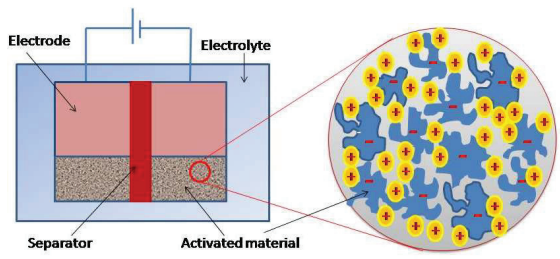

Figure 1: The schematic of activated $\mathrm{MnO}_{2}$ nanoparticles on supercapacitor electrode.

$\mathrm{MnO}_{2}$ nanoparticles are synthesized by simple chemical precipitation method by taking $\mathrm{MnSO}_{4}$ and $\mathrm{KMnO}_{4}$ as starting materials. The structural formation of as- prepared and annealed $\mathrm{MnO}_{2}$ nanoparticles are confirmed by XRD analysis. The functional group and formation of chemical bond between metal ion and oxygen are studied by Fourier transform infrared spectroscopy (FTIR) The surface area of the samples is measured using BrunauerEmmett-Teller (BET) method. Finally electrochemical properties are evaluated using cyclic voltammetry (CV) and galvanostatic charge-discharge techniques.

Typical cyclic voltammetry curves and galvenostatic charge discharge plots are shown in Figure 2 and Figure 3, respectively. The rectangular type $\mathrm{CV}$ curve and symmetry in anodic and cathodic direction are the indication of the ideal capacitive behavior of the electrode materials [2]. As the sweep rate increased, the current response increased with a small distortion in the rectangular shape. This clearly reflects the capacitor behavior.

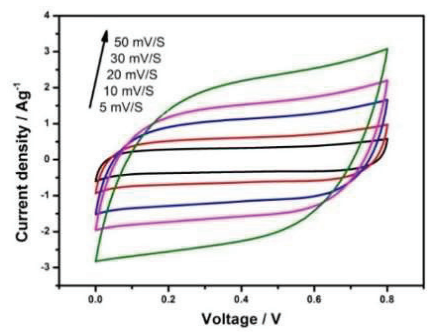

Figure 2: The cyclic voltammogram recorded for asprepared $\mathrm{MnO}_{2}$.

The galvanostatic charge-discharge techniques were employed to investigate the specific capacitance of prepared $\mathrm{MnO}_{2}$. The measurement was carried out in $0.1 \mathrm{M} \mathrm{Na}_{2} \mathrm{SO}_{4}$ aqueous solution at different current densities in the potential range 0 to $0.8 \mathrm{~V}$. A good linear variation in charge-discharge curve is observed for all samples, which is another typical characteristic of an ideal capacitor. Again the symmetry between the charge-discharge curves implies high reversibility and high Coulombic efficiency of the material.

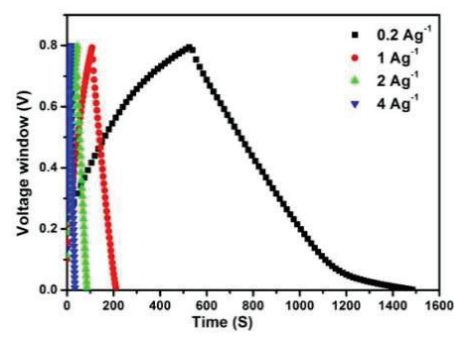

Figure 3: The galvenostatic charge-discharge curve recorded for as-prepared $\mathrm{MnO}_{2}$ at different current densities.

\section{References}

1. Yong Qiun, Shunbao Lun and Fenglei Gao, $J$. Mater Sci. 46:3517-3522 (2011).

2. C. N. R. Rao, S. R. C. Vivekchand, K. Biswas, and A. Govindaraja, Dalton Trans. 34, 3728 (2007) 